\title{
Ranking Environmental Risks for Promoting HSE Management, Case Study: Oil and Gas Projects
}

\author{
SasanAryaee ${ }^{1}$, Mehdi Ravanshadnia*2 \\ ${ }^{1}$ M.Sc, Department of civil engineering, science and research branch, Islamic Azad University, Tehran, Iran , phone: +61- \\ 416-655528; e-mail: aryaeesasan@ gmail.com \\ ${ }^{2} \mathrm{PhD}$, Department of civil engineering, science and research branch, Islamic Azad University, Tehran, Iran, phone: \\ +989121071695; e-mail: ravanshadnia@gmail.com
}

\begin{abstract}
Today, all countries have concluded that health, safety and the environment must be in priority for achieving the sustainable development. Fortunately, allocating the fifth and seventh chapters of Iran's fourth five-year development plan to protect the environment and promote health and improve the quality of life are also indicative of the country's approach to the HSE.In the present study, a model has been presented to identify and prioritize the environmental risks of oil and gas projects. The statistical population of the study consists of all executives active in the oil and gas fields that the statistical sample is selected randomly. In the framework of the proposed method, environmental risks of oil and gas projects were first extracted, then a questionnaire based on these indices was designed based on Likert scale and distributed among the statistical sample. After assessing the validity and reliability of the questionnaire, the effect of each factor was evaluated using the correlation test. Then, the environmental risks of oil and gas projects were ranked using the VIKOR method of multiple-criteria decision-making. The results showed that all 10 identified risks are effective on promoting HSE management. It was concluded from the VIKOR technique that the most important options that caused the reduction of probability of occurring risks and personal injuries and casualties was the entering of dye to the environment when painting the generator pond and the presence of the rigger near the crane. Other cases were placed in the next ranks.
\end{abstract}

Keywords: Oil and Gas Projects, HSE Management, Environmental Risks

\section{Introduction}

Today, all countries have concluded that the human, community and the environment health must be in priority for achieving the sustainable development. hopefully, the fifth and seventh chapters of Iran's fourth five-year development plan is allocated to solve the environmental concerns and promote health toincrease the quality of life are also indicative of the country's approach to the HSE. [2]

One of the most important problems that managers face with, especially in developing countries, is the selection and management of health, safety and environmental programs of the organizations under their management. Because organizations, like human being, have different periods of organizational life that each of them has its own specific needs and features. Health, safety and environmental management systems is a tool to reduce the adverse impacts of industry on humans and the world. If the management system is properly implemented and the performance of all its components is followed, the organizational activities of the management system will become behavior for all individuals at different levels of management [1].

It is required to balance among health and occupational health for achieving sustainable and healthy development during economic development, and this issue should be considered more in the planning process of the country's development. It should always be considered that the three categories of health, safety and the environment have synergistic effects, and their simultaneous effect on labor productivity will be wider. In the world after World War II, there has been a discussion of the integration of these three issues and it has been seriously acted based on it so far, so that the integrated implementation of HSE in a society is considered the symbol of civilization and the level of culture of the community. The absence of any of them can have a negative impact on the integrity of this integrated management system [2]. 


\section{Management of Health, Safety and Environment Management}

Health and safety has been proposed since 1885, and wherever safety is proposed, there is talk of health and the environment. In the US Labor Code, adopted in 1970, a section entitled "Wright Tono" is included that stipulates the right of employees to recognize the risks and problems of their workplace [3].

Security Department in US was established in 1969 titled Personnel Department and today has been renamed the Human Resources Department. In the mid-1970s, the demand for safety services increased dramatically and its organizational position was placed in the administrative deputy. Security Risk Management Department (SRM) was formed to receive its initial information from the workplace inspection and security risk management committees and their most important task was the prevention and control of casualties and losses, and the department's mission was performed in accordance with the rules of OSHA (Occupational Safety and Health Administration). The "IndustrialEnvironment" Health Department was created in 1970 by the merger of the Industrial and Environmental Health Departments. In 1979, the issue of Toxicology was added to the department. Since then, by merging other disciplines of university, the number of environmental health departments was reduced from 9 to 5, and since 1995, the Department of Environmental Health become a unified system by incorporating the nutrition discipline to the HSE department in US [4].

Formal activities in the field of occupational health and safety in the country dates back to 1325 coinciding with the establishment of the Ministry of Labor and Social Affairs and the developing of the Labor Code. In 1337, the law was approved with modifications and changes as the law that the duties related to the occupational safety and health were assigned to the General Inspectorate of Labor. One of the most active agencies of HSE in the country is the Ministry of Oil. In late 2001, following the emphasis of the Minister of Petroleum to establish the HSE management system in this ministry, the Central Council for Safety and Fire Supervision approved the selection and translation of the HSE-MS (Health, Safety and Environment Management System) guidelines developed by the Oil and Gas Producers Association [5].

\section{Health, Safety and Environment Management in Oil and Gas Industries}

An HSE management system in industrial environments can be effectively implemented and achieve its goals to prevent accidents, reduce financial damage and causalities, preserve resources and the environment and enhance performance and pay enough attention to the factors such as senior management commitment, responsibility of management and staff, employees' participation, risk identification and control, research about incidents, training and periodic evaluation of system [5].

Given the central role of health in the HSE and that the great goal of each of these three issues is to preserve human health and life, more serious attention should be paid to the field of health. An HSE management system in industrial environments can effectively achieve its goals to prevent incidents, reduce financial losses and injuries, preserve resources and the environment, and increase work efficiency. For this reason, it is necessary to systematically identify and assess the risks threating individuals, the environment and property and the actions reducing them to be implemented, it is required to perform any action to protect the physical health of the workforce [14].

Health risks are systematically assessed to take appropriate measures. Personnel competency is regularly evaluated and the appropriate training programs are regulated and implemented. Any type of incident, quasi-accident or unsafe situation should be reported in writing and analyzed and the appropriate performance to be done to prevent them from re-occurring. Experience from this analysis should be systematically communicated to all operational units and used in the readiness for future operations [15].

The implementation of the HSE policy should be controlled periodically in each activity. HSE efficiency should also be assessed when performing internal audits, inspections and reviews. In order to implement the HSE culture in an organization, it should be determined a particular value, reinforced the commitment of executives, and held appropriate training courses for all the organizational levels. According to the key role of contractors in the operations of the country's oil and gas industries, it is reasonable that corporate executives to consider management in the aspects of occupational health, safety and environment of their company specially, contractors according to the attention to other 
management aspects such as quality, economics, technology and production. The evaluation and selection of contractors and practitioners should be explored in terms of their efficiency in the HSE field. Their responsibilities for the HSE need to be clearly explained in the contracts, because improvement in the overall performance of the organization is not possible without investigating these aspects [17].

Investigating the experiences of successful oil companies of the world shows that investing on health, safety and environment has a top priority, and the environmental issue is a constant concern in the exploration and production of all levels of the organization. Therefore, it is important and essential to consider the safety and health of those involved in these projects. It is hoped that with the full implementation of the HSE policy by organizations and the implementation of the HSE rich culture by executives and experts in this field, we will soon see a more prosperous and productive management of the health, safety and environment of Iran's oil and gas industries. [2].

\section{A Review of the Literature of Environmental Risks}

Agha Razi (1997) introduced insurance for environmental risk management. According to their view, during the production and operation of industrial companies, incidents occur due to the destruction of equipment or other uncontrollable factors. These incidents may lead to the loss of assets as well as environmental damage. Incidents that cause environmental pollution can have a significant impact on natural resources. Governments expect companies to properly manage their environmental risks and to compensate for any damage caused by the fault in managing those risks. As a result, insurers need to assess to what extent a company's risk management processes determine the environmental risks involved in company's activities.

The new insurance product has been released titled environmental pollution liability and safety liability insurance that supports environmental and safety risk control and prevention systems. In their research, they examine a new insurance product in this field by investigating the various aspects of environmental pollution and its relationship with insurance [16].

Omidvari and Shahbazi in their research evaluated the safety, health and environmental risks in hospitals affiliated to ShahidBeheshti University of Medical Sciences and finally presented control strategies. In the research, in the first step, the main risks in hospitals were identified and based on FMEA logic, an index of severity, probability and vulnerability was identified for each risk. Prioritization criteria were then determined and the priority of risks was performed using fuzzy network analysis. The results of this study showed that in terms of risk priority number in hospitals, the highest priority was related to biological factors affecting human and the least risk was related to physical factors affecting human. The results also showed that the risk priority of various factors affecting the reputation of the organization had high relative priorities. Thus, the results showed that hospital management should adopt specific management plans with two approaches of organizational health and reputation regarding control of the chemical and biological factors. It is also specified from the results that ergonomic workplace programs need to be considered by the management and the control measures to be defined in that area.

Khatami Firouzabadihave determined the most important project risk categories considering the causal relationships between them in the fuzzy environment. This study seeks to determine the most important risks within the framework of the risk-failure structure of the Fourth Edition of the Guide to the Project Management Knowledge, which can be generalized to all aspects included in the project definition at national level. Due to the fact that project risks have interactions with each other, the DEMATEL method was used to determine the most important categories of project risk according to the structure of risk failure considering causal relationships. The fuzzy set theory was also used to obtain the subjective opinions of experts that had sufficient experience and knowledge at the level of national projects.The results indicated that the "external", "technical", "project management" and "organizational" risk categories are the most important risk categories respectively and in the most important category, i.e "external" risks, the risks affected by regulatory laws, in the category of "Technical" risks, the risks related to "technology", in the category of risks of the "project management", risks related to the "estimation" and in the "organizational" risks, risks related to the "project dependencies" are in the first rank of importance.

Jebel Amoli, Haddad and Haji Agha Bozorgi presented an applied model called Comprehensive Risk Management Cycle to evaluate the financial risk of projects. They believe that risk management is used to maximize positive outcomes and 
minimize the likelihood of project consequences and adverse effects. Projects are exposed to crisis due to current market and business conditions and uncertainties. So risk management can be said to be a prerequisite for achieving project goals.

Khazayni and Afshar have provided a guide framework for how risk sharing among project agents by showing the position of the risk sharing process in the formation of a project. According to the results, the government by having a standardized structure will make the negotiations to be shorter and lead to the leadership outcome, and the project (from financing and implementation to operation and sales) will be easy and low cost.

MonirAbbasifirst determined the main risks that investors and lenders are faced in the projects, especially in developing countries, such as Iran, and then described some of the ways in which investors and lenders try to reduce these risks. On this basis, the private sector usually tends to accept the risks that think it has the most control over, and seeks to government support for risks that seem to have less control.

Marcelinosadaba in their paper examined the project risk management approach in small companies. They have presented a methodology for risk management in Spain that includes factors that are usually overlooked in small companies. Their model consists of tools, checklists, and so on that executed on 72 companies. The results of implementing the model presented to companies have shown that implementation of this model reduces time, cost and improve management processes.

Fong and Marl propose a simulation-based risk network model for decision support in project risk management. This model helps managers to review and re-evaluate risks according to their priorities and to make decisions based on the results of the evaluation. They used real data to test the model and assess the risk response. The results of the simulated model implementation indicated the validity of the model.

\section{Research Method}

Multi-criteria decision-making methods that have been considered by the researchers in the last 30 years have been used from multi-criteria of measurement rather than optimality measurement criteria. Multi-criteria decision making models are divided into two main categories: multi-objective diffusion models and multi-attribute decision making. Generally, multi-objective models are used to design and multi-objective models are used to select the best option. The main difference between multi-objective decision models and multi-criteria decision models is that the former are defined in the continuous decision space and the latter defined in discrete decision space [6].

The purpose of multi-attribute decision-making models is to select (evaluate) the best option among the finite number of options (sometimes instead of option, synonyms of strategy are used, etc.). In addition to the options, there are several indices that the decision maker must specify in his or her own issues. These indices are examined in relation to each option [7].

The output of multi-attribute decision-making models will be an option that provides the most preferred value or utility of any existing attribute. Note also that access to the optimal option is impossible in most cases, but choosing the most appropriate option will be relatively feasible in any case. As a result, the output of multi-attribute decision making models makes the order and priority of the options available in the decision matrix available relative to each other [12].

In this study, VIKOR method was used to rank and evaluate environmental risks in oil and gas projects. This method can provide a maximum value of group desirability for the majority and a minimum value of single effect for the opposition [13].

For conducting this method, we first normalize the initial decision matrix. Next, we determine the positive ideal answer (the highest priority option) and the negative ideal answer (the lowest priority option), then we calculate the distance of the options from the ideal solutions and calculate the amount of VIKOR and then rank and decide on the options [8].

In fact, the VIKOR model prioritizes or ranks options by evaluating criteria-based options. In this model, the criteria are not weighted, but criteria are evaluated by other methods, and then the options are evaluated and ranked based on the criteria and the combination in the value of criteria. This method can provide a maximum value of group desirability for the majority and a minimum value of individual influence for opposition [9]. 
This approach is one of the multi-criteria decision-making methods for solving a discrete decision problem with improper criteria developed to optimize the multi-criteria complex systems. This method focuses on the sorting and selection selection of a set of options and determines the adaptive responses to a problem with conflicting criteria. The main purpose purpose of this method is to determine the weight and value of each option and rank it so that it can help decision makers to to make a final decision. Here, the compromise answer is the closest justified answer to the ideal answer that the word compromise refers to as a mutual agreement [10]

Considering the use of the VIKOR method in this study, it is necessary to consider the criteria. The criteria that are investigated in assessing and ranking the environmental risks of oil and gas projects are:

- Probability of risk occurrence

- Impact on project cost

- Impact on project time

- Impact on personal injury and causalities.

Also, based on the literature review, the most important environmental risks of oil and gas projects are[11]:

1. Collision of machinery and equipment with oil or gas pipeline during excavation

2. Rigger's presence near the crane

3.Collision of machinery and equipment with underground electrical installations during excavation

4.Injection of acidic and chemical substances

5.Radiation during radiography

6. Contact with molten bitumen and breathing smoke and fumes caused by bitumen

7. Contact with UV during welding

8. Oil spill during flushing

9.Entering dye into the environment when painting a generator pool

10. Launching welding sparks.

In this research, first, using the library method and referring to specialized Persian and Latin books and journals and valid scientific sites, the data and basic information needed were collected to formulate the theoretical foundations of the research and then the information needed to rank the ten risks identified was collected using a researcher-made questionnaire.

In MADM techniques, the objective is to evaluate the options based on the criteria and to select the optimal option. In this model, the criteria are not weighted but the weight of the criteria is obtained from other methods and used as input.

Table 1. Weight of options

\begin{tabular}{|c|c|c|}
\hline Weight & Symbol & Scale \\
\hline 1 & VL & Very low \\
\hline 3,2 & L & Low \\
\hline 4,3 & ML & Relatively low \\
\hline 4,5 & $\mathrm{M}$ & Medium \\
\hline 5,6 & $\mathrm{MH}$ & Relatively high \\
\hline $6,7,8$ & $\mathrm{H}$ & High \\
\hline 9 & $\mathrm{VH}$ & Very high \\
\hline
\end{tabular}

The evaluation of options is based on criteria by the decision matrix. There are always several options in this model that are evaluated based on multi-criteria independently and ultimately, the options are ranked by value.

The statistical population of the study includes all managers active in the fields of oil and gas that the statistical sample is selected randomly. Different methods are used to determine sample size in research. Cochran formula was used to determine sample size in this study. Thus, considering 250 for the statistical population, the minimum sample size is 150 persons.

Content validity and face validity were used to determine the validity of the questionnaire. Waltz and Bausellmethod was used to investigate the content validity index. In this way, the experts identified the "relevance", "clarity" and "simplicity" 
of each question on a scale. The minimum acceptable value for this index was 0.79 . In the present questionnaire, all the questions obtained this value and therefore the content validity of the questionnaire was confirmed.

To investigate the face validity, the opinions of the target sample group or research respondents are used, and this of the validity of the test does not require the opinions of experts. To assess the impact scores, participants were first to specify the importance of each question on a five-point Likert scale ranging from 1 (not at all important) to 5 (quite important). To accept the face validity of each question, its impact score must not be less than 1.5, and only questions acceptable in terms of face validity that have a score above 1.5 that all questions in the present study have an impact score greater than this value. Therefore, the face validity of the research questionnaire was confirmed.

Cronbach's alpha method was used to measure reliability. The Cronbach's alpha method is used to measure the internal reliability of an index's items, mainly for questionnaires that its questions are designed in spectrum and its answers are multi-option. The Cronbach's alpha for the present questionnaire is 0.782 , which is greater than 0.7 and confirms the reliability of the questionnaire.

\section{Data Analysis}

In this study, the normality of the data should be investigated first, to the appropriate test to be selected for investigating the variables. The Kolmogorov-Smirnov test is used to investigate the normality of the data and for this purpose, it compares the observed cumulative distribution function with the expected cumulative distribution function. In other words, in this test, the distribution of an attribute in a sample is compared with the distribution that is assumed for that population. This test is used as a distribution match test for quantitative data and determines whether this sample is obtained from a normal distribution society?

Table 2. Test results of normality of distribution of the research variables

\begin{tabular}{|c|c|c|c|}
\hline sig & $\begin{array}{c}\text { Index } \\
\text { K-S }\end{array}$ & Risks & Line \\
\hline 0.00 & 2.208 & $\begin{array}{c}\text { Collision of machinery and equipment with } \\
\text { underground electrical installations during excavation }\end{array}$ & 1 \\
\hline 0.00 & 2.520 & Rigger's presence near the crane & 2 \\
\hline 0.00 & 2.727 & $\begin{array}{c}\text { Collision of machinery and equipment with } \\
\text { underground electrical installations during excavation }\end{array}$ & 3 \\
\hline 0.00 & 2.842 & Injection of acidic and chemical substances & 4 \\
\hline 0.00 & 2.427 & Radiation during radiography & 5 \\
\hline 0.00 & 2.693 & $\begin{array}{c}\text { Contact with molten bitumen and breathing smoke } \\
\text { and fumes caused by bitumen }\end{array}$ & 6 \\
\hline 0.00 & 2.601 & Contact with UV during welding & 7 \\
\hline 0.00 & 2.850 & Oil spill during flushing & 8 \\
\hline 0.00 & 2.625 & $\begin{array}{c}\text { Entering dye into the environment when painting a } \\
\text { generator pool }\end{array}$ & 9 \\
\hline 0.00 & 2.480 & Launching welding sparks. & 10 \\
\hline
\end{tabular}

According to Table 2, since the significance level (sig) for hypothesis questions is less than 0.05 , the null hypothesis (based on data normality) is rejected, and we conclude that the distribution of data across all variables is not normal, so in order to examine the correlation between the variables, Spearman correlation coefficient was used. 
Table 3. Spearman correlation test results for the research variables

\begin{tabular}{|c|c|c|c|}
\hline Sig & $\begin{array}{c}\text { Spearman's } \\
\text { coefficient }\end{array}$ & Risk & Line \\
\hline 0.000 & 0.682 & $\begin{array}{c}\text { Collision of machinery and equipment with underground electrical } \\
\text { installations during excavation }\end{array}$ & 1 \\
\hline 0.000 & 0.354 & $\begin{array}{c}\text { Rigger's presence near the crane } \\
\text { installations during excavation }\end{array}$ & 2 \\
\hline 0.000 & 0.482 & $\begin{array}{c}\text { Collision of machinery and equipment with underground electrical } \\
\text { Injection of acidic and chemical substances }\end{array}$ & 3 \\
\hline 0.000 & 0.755 & Radiation during radiography & 5 \\
\hline 0.000 & 0.683 & $\begin{array}{c}\text { Contact with molten bitumen and breathing smoke and fumes } \\
\text { caused by bitumen }\end{array}$ & 6 \\
\hline 0.000 & 0.708 & Contact with UV during welding & 7 \\
\hline 0.000 & 0.670 & Oil spill during flushing & 8 \\
\hline 0.000 & 0.671 & Launching welding sparks. & 9 \\
\hline 0.000 & 0.411 & Entering dye into the environment when painting a generator pool & 10 \\
\hline 0.001 & 0.266 & &
\end{tabular}

According to Table 3, correlation coefficients are significant at error level less than 0.05. Therefore, the research variables are confirmed,it means that the selected risks have a significant impact on the HSE management of oil and gas projects. Given the impact of all identified risks on the HSE management of oil and gas projects, these risks will be ranked using the VIKOR method.

1) Initial Decision Matrix Formation:

The initial decision matrix is obtained from the geometric mean of the respondents' comments as described in Table 4.

Table 4. VIKOR's initial decision matrix

\begin{tabular}{|c|c|c|c|c|}
\hline $\begin{array}{c}\text { Impact on personal injuries and } \\
\text { causalities }\end{array}$ & $\begin{array}{c}\text { Impact on the } \\
\text { time of project }\end{array}$ & $\begin{array}{c}\text { Impact on the } \\
\text { cost of project }\end{array}$ & $\begin{array}{c}\text { Probability of } \\
\text { occurrence }\end{array}$ & Risk \\
\hline 9 & 3 & 2 & 8 & F1 \\
\hline 7 & 4 & 3 & 8 & F2 \\
\hline 5 & 2 & 2 & 7 & F3 \\
\hline 3 & 1 & 2 & 5 & F4 \\
\hline 5 & 2 & 3 & 1 & F5 \\
\hline 2 & 1 & 2 & 2 & F7 \\
\hline 1 & 5 & 4 & 2 & F8 \\
\hline 8 & 2 & 5 & 3 & F9 \\
\hline 8 & 5 & 6 & 2 & F10 \\
\hline 4 & 2 & 2 & & \\
\hline
\end{tabular}

2) Normalizing or non-scaling the initial decision matrix:

Using the linear normalization formula, all of the matrix values are multiplied by 2 and the sum of each column is summed and then the square root is obtained and finally, each value is divided by the obtained square root. The results of this step can be seen in Table 5 .

Table 5. Normal initial decision matrix 


\begin{tabular}{|c|c|c|c|c|}
\hline $\begin{array}{c}\text { Impact on personal injuries and } \\
\text { causalities }\end{array}$ & $\begin{array}{c}\text { Impact on the } \\
\text { time of project }\end{array}$ & $\begin{array}{c}\text { Impact on the } \\
\text { cost of project }\end{array}$ & $\begin{array}{c}\text { Probability of } \\
\text { occurrence }\end{array}$ & Risk \\
\hline 0.489535464 & 0.311085508 & 0.186500962 & 0.529812943 & F1 \\
\hline 0.380749805 & 0.414780678 & 0.279751442 & 0.529812943 & F2 \\
\hline 0.271964147 & 0.207390339 & 0.186500962 & 0.463586325 & F3 \\
\hline 0.163178488 & 0.103695169 & 0.186500962 & 0.132453236 & F4 \\
\hline 0.271964147 & 0.207390339 & 0.279751442 & 0.331133089 & F5 \\
\hline 0.108785659 & 0.103695169 & 0.186500962 & 0.066226618 & F6 \\
\hline 0.054392829 & 0.518475847 & 0.373001923 & 0.132453236 & F7 \\
\hline 0.435142635 & 0.207390339 & 0.466252404 & 0.132453236 & F8 \\
\hline 0.435142635 & 0.518475847 & 0.559502885 & 0.198679854 & F9 \\
\hline 0.217571317 & 0.207390339 & 0.186500962 & 0.132453236 & F10 \\
\hline
\end{tabular}

3) Determining the ideal positive and negative points:

At this point, the best and worst value of each option is determined. These values are visible in Table 6.

Table 6. Ideal Positive and Negative Point

\begin{tabular}{|c|c|c|c|c|}
\hline $\begin{array}{c}\text { Impact on personal } \\
\text { injuries and causalities }\end{array}$ & $\begin{array}{c}\text { Impact on the time of } \\
\text { project }\end{array}$ & $\begin{array}{c}\text { Impact on the cost of } \\
\text { project }\end{array}$ & $\begin{array}{c}\text { Probability of } \\
\text { occurrence }\end{array}$ & Option \\
\hline 0.489535464 & 0.518475847 & 0.559502885 & 0.529812943 & Positive ideal \\
\hline 0.054392829 & 0.103695169 & 0.186500962 & 0.066226618 & Negative ideal \\
\hline
\end{tabular}

4) DeterminingS and R:

Using the relative distance formula, the $\mathrm{i}$-option of the ideal point is equal to $\mathrm{S}$ and the maximum inconvenience of the i-option of distance from the ideal point is calculated equal to $\mathrm{R}$. These values are listed in Table 5.

Table 7. Determining the index of benefit and regret

\begin{tabular}{|c|c|c|}
\hline Regret $(\mathrm{R})$ & Benefit $(\mathrm{S})$ & Risk \\
\hline 1.5 & 1 & F1 \\
\hline 1.25 & 0.75 & F2 \\
\hline 2.392857143 & 1 & F3 \\
\hline 3.607142857 & 1 & F4 \\
\hline 2.428571429 & 0.75 & F5 \\
\hline 3.875 & 1 & F6 \\
\hline 2.357142857 & 1 & F7 \\
\hline 1.982142857 & 0.857142857 & F8 \\
\hline 0.839285714 & 0.714285714 & F9 \\
\hline 3.232142857 & 1 & F10 \\
\hline
\end{tabular}

5) DeterminingQ value and ranking of executive risks:

By determining $\mathrm{Q}$, the options are sorted and ranked in descending order. The best rank is for an option with the lowest $\mathrm{Q}$. The values of this index are visible in Table 8. 
Table 8. Determining VIKOR Index and Ranking of Options

\begin{tabular}{|l|l|l|}
\hline VIKOR index $(\mathrm{Q})$ & Risk & Rank \\
\hline 0.608823529 & F1 & 5 \\
\hline 0.130147059 & F2 & 2 \\
\hline 0.755882353 & F3 & 7 \\
\hline 0.955882353 & F4 & 9 \\
\hline 0.324264706 & F5 & 3 \\
\hline 1 & F6 & 10 \\
\hline 0.75 & F7 & 6 \\
\hline 0.438235294 & F8 & 4 \\
\hline 0 & F9 & 1 \\
\hline 0.894117647 & F10 & 8 \\
\hline
\end{tabular}

6) Two final conditions of the VIKOR technique:

Condition One: Establishing the following equation:

$$
Q\left(a^{\prime \prime}\right)-Q\left(a^{\prime}\right) \geq D Q
$$

Where $a^{\prime}$ is the first option and $a^{\prime \prime}$ is the next option, and $D Q=\frac{1}{n-1}$ and $n$ indicates the number of options. This value is:

$0.130147059-0 \geq \frac{1}{10-1}$

\section{$0.130147059 \geq 0.111111111$}

- The first condition is established.

Condition two: The option that has the lowest value of the VIKOR index (ie F9) must have at S or R the least value. This is established for F9 and in both cases, $\mathrm{S}$ and $\mathrm{R}$ has the lowest value.

- The second condition is established.

As such, the rankings made by the VIKOR method are acceptable and can be interpreted.

The final ranking obtained can be seen in Table 9:

Table 9. Environmental risk ranking of oil and gas projects

\begin{tabular}{|l|l|}
\hline Risk & Rank \\
\hline Entering dye into the environment when painting a generator pool & 1 \\
\hline Rigger's presence near the crane & 2 \\
\hline Radiation during radiography & 3 \\
\hline Oil spill during flushing & 4 \\
\hline Collision of machinery and equipment with oil or gas pipeline during excavation & 5 \\
\hline Contact with UV during welding & 6 \\
\hline $\begin{array}{l}\text { Collision of machinery and equipment with underground electrical installations during } \\
\text { excavation }\end{array}$ & 7 \\
\hline Launching welding sparks. & 8 \\
\hline Injection of acidic and chemical substances & 9 \\
\hline Contact with molten bitumen and breathing smoke and fumes caused by bitumen & 10 \\
\hline
\end{tabular}




\section{Conclusion}

Project's Risk Management is one of the major topics of project management that involves planning, organizing, monitoring and controlling all aspects of a project, including risk identification, measurement, risk response and risk response control.It is important to note that before the risk identification, it is not possible to determine the or negative consequences of the project objectives, and this alone is one of the important factors in project under uncertain conditions. The certain risks can be planned and managed after identification and analysis, while the uncertain risks of each project (even relying on the experiences of executors in previous similar projects or applying techniques with contingent approach) are not manageable. Some of the risks identified in the project affect the HSE management, so this study is conducted to present a model of environmental risk ratings of oil and gas projects to promote HSE.

It was concluded from the results in VIKOR technique that for planing HSE of oil and gas projects, the options that reduce the probability of occurring risks and personal injuries and causalities more than other options and less than the other options are costly for the project and will add less time to the project is the entering of dye to the environment when painting the generator pond and the presence of a rigger near the crane.

To reduce the harmful effects of these two risks, it is recommended to use safety signs. Safety signs are one of the cheapest and easiest ways to control and prevent risks.Installing safety signs in workshops is subject to labor law that in these regulations, it is tried to cover all applicable general safety signs in the workshops to point out the hazards that may be in the workplace to workers and public people which are present in that environment.

In large industries, it is almost impossible all employees to be familiar with all the dangers and all the places due to the experience. On the other hand, workers and employees may move from one unit to another and do not have the enough opportunity to identify their workplace risks. Installing safety signs in the workplace can expedite the process of introducing risks to employees. Safety signs provide information in the form of guidelines related to industry hazards and injuries. These signs can be effective if their design conforms to the principles of ergonomics and based on cognitive features of design.

Safety signboard information plays an important role in promoting industrial safety, controlling the behavior of engineers and workers in the form of guidelines related to hazards and industry injuries. Now, the equipment can be effective, if they are designed in accordance with ergonomic principles and based on the human factors, otherwise the problem in the information processing process will in turn increase the likelihood of unsafe behavior by the worker. In total, it is important to note that signs must be designed so that they are clearly visible, recognizable, and understandable, and they may result in death or serious injury if they are not fully and effectively showed.

\section{Reference}

[1] Amiri, Maghsoud (2013). Providing a Method for Ranking Project Activity Risk Using CPM Network and TOPSIS Method in Fuzzy Mode, Industrial Management Perspective, No. 10, pp. 183- 169.

[2] BarkhordariAhmadi, Mahnaz.,Jamali, Ebrahim. (2017). Hazard Identification of Oil Projects Based on PMBOK Standard and Their Ranking by AHP and TOPSIS Approach in Fuzzy Environment, Technology Growth, Volume 13, Number 50, 50-41.

[3] Alborz, ER (2004). Insurance Risk Management and Offshore Facility, Journal of Health, Safety and Environment Management System, Nefa Offshore Iran Company, No. 10, 8-9.

[4] Bidi, Abbas. (2008). Risk Management of Civil Projects by Applying Contractual Considerations, Fourth International Project Management Conference.Ariana Research Group.

[5] Khazaini, Garshasb.,Afshar, Abbas. (2005). Risk sharing, the basis of risk management in BOT projects, 4th International Conference of Industrial Engineering.

[6] Dana, Toraj. (2004). A Look at the Position of the Environment in Governmental Organizations, Green Organization, Petro Pars Journal, Issue 7, 28-29.

[7] Roayai, AS. (2005). Stablishing an Integrated Health and Environmental Safety System at National Iranian Oil Company, HSE National Conference on Safety Engineering and Management, Sharif University of Technology. 
[8] Mohammad Beigi, Majid., Lori, Alireza., Talouri, Abdul Rasoul. (2018). Identifying and Ranking Risk Management in Reducing Costs of Implementing Construction Projects in the Oil and Gas Industry, Fourth National Conference on Urban Planning, Architecture, Civil and Environment, Shirvan, Research Institute of RahjouyanPayaShahrAtrak

[9] Momeni, Mansour. (2006). Recent Issues in Operations Research, University of Tehran School of Management, Tehran. [10]Wazdani, Soghra, SabzGhobaiy, Gholamreza. Dashti, Sulmaz, Cheraghi, Mitra. Alizadeh, Reza. Hemmati, Azam. 2018. Application of FMEA Model for Environmental, Safety and Health Risks Assessment of Parsian Gas Refinery Storage Tanks in 2016. Journal of Rafsanjan University of Medical Sciences. Issue 17, Volume 4, pp. 345-358

[11] Acebes, F., Pajares, J., Manuel Galán, J., López-Paredes, A. (2014). A new approach for project control under uncertainty.Going back to the basics, International Journal of Project Management, 32, 423-434.

[12] Doumpos, M., \&Grigoroudis, E. (2013). Multi-criteria Decision Aid and Artificial Intelligence. Whiley (UK).

[13] Fu-zhou. L., Hong-yuan, G. (2011).The risk assessment model of BT construction engineering project financing, Systems Engineering Procedia, 1, 169-173.

[14] Huang, J. J., Tzeng, G. H., \& Liu, H. H. (2009). A revised VIKOR model for multiple criteria decision making-The perspective of regret theory. In International Conference on Multiple Criteria Decision Making (pp. 761-768).Springer, Berlin, Heidelberg.

[15] Liu, H., \& Yan, T. (2007, August). Bidding-evaluation of construction projects based on VIKOR method.In 2007 IEEE International Conference on Automation and Logistics (pp. 1778-1782).IEEE.

[16] Shaluf I, Abdullah S. Floating roof storage tank boilover.J of Preve in the Process Indus 2010; 3: 1- 7.

[17] Teller, J., Unger, B. N., Kock, A., \&Gemünden, H. G. (2012). Formalization of project portfolio management: The moderating role of project portfolio complexity. International Journal of Project Management, 30(5), 596-607. 